\title{
Awareness and Pharmacotherapy of Hypertension in a Rural Community
}

\author{
Fiona White $^{\mathrm{a}}$ Lexin Wang $^{\mathrm{a}}$ Herbert Jelinek $^{\mathrm{b}}$ \\ a School of Biomedical Sciences, Charles Sturt University, Wagga Wagga, N.S.W., and bSchool of Community Health, \\ Charles Sturt University, Albury, N.S.W., Australia
}

\author{
Key Words \\ Hypertension · Awareness · Pharmacotherapy • Rural \\ community
}

\begin{abstract}
Objective: To determine the level of awareness of hypertension and pharmacological management in patients from a rural community of Australia. Subjects and Methods: A total of 665 patients were studied. The patients were recruited from Albury-Wodonga and surrounding districts, which are located in a rural area of south-eastern Australia. Demographic information and medical history were recorded for all patients. Clinical data were also recorded. Results: Of the 665 patients, 449 (75\%) were hypertensive, and of these 449 hypertensive patients, 195 (43.4\%) were aware that they had hypertension. Blood pressure was inadequately controlled in 399 of the hypertensive patients (88.9\%) according to the management guidelines of the National Heart Foundation of Australia. Of all the patients who had hypertension, 247 (55.0\%) were not receiving antihypertensive therapy. Of those receiving therapy, 132 (65.3\%) were being administered only one antihypertensive (monotherapy). The most commonly prescribed antihypertensive classes were angiotensin-converting enzyme inhibitors, angiotensin II receptor antagonists, diuretics, $\beta$-blockers and calcium channel blockers. Conclusion: The level of awareness of hypertension and its management appeared to be poor in hypertensive patients living in this rural Australian community. Actual hypertension control was extremely poor, and a major
\end{abstract}

\section{KARGER \\ Fax +41613061234 \\ E-Mail karger@karger.ch}

www.karger.com
(C) 2009 S. Karger AG, Basel

1011-7571/09/0184-0261\$26.00/0

Accessible online at:

www.karger.com/mpp potential cause of this may be the poor use of anti-hypertensive medications in these patients. Strategies to improve the awareness of hypertension and its required management in patients residing in rural communities are recommended.

Copyright $\odot 2009$ S. Karger AG, Basel

\section{Introduction}

Australia has a population of approximately 21 million people, with an estimated one third residing in rural areas [1]. Australia's population and life expectancy continue to increase [1], thereby intensifying the importance of appropriate disease management.

Hypertension is one of the most common diseases in Australia, with a prevalence of $28.6 \%$ in adults [2]. It is one of the most frequently managed problems, responsible for $8.6 \%$ of all patient-doctor encounters and $7.9 \%$ of all medication prescriptions [2]. Hypertension has known links with other conditions such as diabetes mellitus and obesity [3], which are reported to be increasing in incidence in Australia [4] and which exacerbate a patient's cardiovascular risk and the need for appropriate management.

Little is known about the level of awareness of hypertension in Australian patients, particularly those residing in rural areas. However, one recent study [5] determined that there was a $62.1 \%$ level of awareness of hypertension in a rural Australian population. In Spain, a significant difference has been reported between rural and urban

Prof. Lexin Wang, MD, PhD

School of Biomedical Sciences

Charles Sturt University

Wagga Wagga, NSW 2678 (Australia)

Tel. +61 26933 2905, Fax +61 26933 2587, E-Mail lwang@csu.edu.au 
patients [6], with rural patients demonstrating a lower level of awareness.

Control of hypertension also appears to be poorer in rural compared to urban areas [7-10]. Several explanations have been proposed for this, including a lack of or poor implementation of guidelines such as those provided by the National Heart Foundation and poor patient compliance with treatment regimes [11-13].

The most common treatment is the use of antihypertensive medications. Of all the hypertensive patients identified in the 1999-2000 AusDiab Study, only 46.9\% were receiving antihypertensive medications, while the remaining 53.1\% were untreated [2]. Of the hypertensive patients receiving antihypertensive treatment, $60.3 \%$ had blood pressure that was above the accepted level of $<140 / 90 \mathrm{~mm} \mathrm{Hg}$, which should have been attained with adequate treatment [2].

Awareness of hypertension and the adequate treatment and management of blood pressure levels in hypertensive patients appear to be poor in Australia, and residing in a rural area appears to worsen these factors further $[2,5]$. The primary objectives of this study were to determine the level of awareness of hypertension in patients living in a rural community and to investigate the pharmacological management of hypertension in this population.

\section{Subjects and Methods}

This study received ethical approval from the Charles Sturt University Human Ethics Committee. Informed written consent was obtained from all participants.

\section{Study Background and Location}

This study was part of a study entitled The Diabetes Screening Complications Research Initiative, which was conducted at the Albury-Wodonga campus of Charles Sturt University. The main objective was to determine the prevalence of risk factors for diabetes complications, as well as the effects of an annual health screening on the community.

Participants were recruited to the Diabetes Screening Complications Research Initiative from Albury-Wodonga and surrounding districts. Albury-Wodonga is a rural inland city with an estimated population of 100,000 persons located on the New South Wales-Victorian border in south-eastern Australia.

\section{Patient Recruitment}

Patients were recruited to the study through a public media campaign involving different kinds of advertisements. These included a newspaper article in the Border Mail, a news story on local television, advertisements in general practice and community health centers and radio. People were requested to contact the university if they wished to undergo a health check and were ac- cepted regardless of whether or not they had known diabetic or cardiovascular disease. An appointment was made to attend the health screening clinic. Each participant who attended received an information sheet and signed an informed consent form to participate in the study and have their collected data used for research purposes $[14,15]$.

Seven hundred and three adult patients attended the health screening clinic. Of these, 38 patients were excluded on the basis of a total absence of any recorded blood pressure measurements, due to surgery, discomfort, recent blood donation, skin disease or choosing not to have their blood pressure measured at the time. The final study population used for analysis amounted to 665 adult patients.

\section{Definitions of Hypertension}

The definitions and guidelines for hypertension used in this study were obtained from the Hypertension Management Guide for Doctors 2004 [11], which was current at the time of the study. Patients were classified as hypertensive if they had a known previous history of hypertension and/or had a blood pressure measurement which was classified as hypertensive according to the 2004 National Heart Foundation guidelines.

\section{Data Collection}

Patient information was collected by means of a demographic and clinical history questionnaire, as well as a clinical examination. The information collected from the questionnaire included age, sex, currently prescribed medications, diabetes status (including type if known), years of diabetes and whether or not there was any known family history of diabetes.

Other information was measured clinically, including blood glucose, body mass index and blood pressure. Blood glucose levels were measured using an Accu-Chek Advantage II glucometer (Roche Australia P/L); body mass index was calculated from the patient's measured height and weight at the clinic and blood pressure measurements were taken using a standard mercury sphygmomanometer (Welsh Allyn). Two blood pressure readings were recorded using a cuff of appropriate size for the patient after (s)he had rested for at least $5 \mathrm{~min}$ in the supine position. If the supine position was not possible, blood pressure was recorded in the sitting position with the arm supported at the height of the heart. A standing blood pressure measurement was also recorded $3 \mathrm{~min}$ after standing from a supine position. For each patient, the mean of two blood pressure measurements taken $1 \mathrm{~min}$ apart was recorded for each position.

All information and clinical measurements were compiled within $1 \mathrm{~h}$ at the one site, with the final part of the visit being a consultation with the research coordinator (H.J.). Here, feedback was provided to patients about their test results, as well as recommendations for follow-up based on the relevant guidelines from the Australian Diabetes Society and the National Heart Foundation of Australia [15].

\section{Statistical Analysis}

All data are presented as means \pm standard deviation. The specific statistical tests used for the analysis were Student $t$ tests for paired samples, ANOVA for more than 3 groups and $\chi^{2}$ test for categorical data such as the awareness and control of hypertension. A p value of less than 0.05 was considered statistically significant in this study. 
Table 1. Cardiovascular risk factors of the total study population $(\mathrm{n}=665)$

\begin{tabular}{ll}
\hline Risk factor & Patients \\
\hline Mean age, years & $60.9 \pm 13.1(23-93)$ \\
Males/females & $285 / 380$ \\
Smoking & $41(6.2 \%)$ \\
Alcohol consumption & $103(15.5 \%)$ \\
Overweight/obese (BMI $\geq 25)$ & $464(69.8 \%)$ \\
Awareness of hypertension diagnosis & $196(29.5 \%)$ \\
Known type 2 diabetes mellitus & $143(21.5 \%)$ \\
Family history of diabetes mellitus & $248(37.3 \%)$ \\
\hline
\end{tabular}

$\mathrm{BMI}=$ Body mass index.
Table 2. Demographic and clinical findings in patients with hypertension $(\mathrm{n}=449)$

\begin{tabular}{lc}
\hline Characteristic & Patients \\
\hline Mean age, years & $63.5 \pm 12.0(23-93)$ \\
Males/females & $198 / 251$ \\
Mean blood glucose level at clinic, mmol/1 & $5.6 \pm 2.6(2.9-26.5)$ \\
Diabetes mellitus & $118(26.3 \%)$ \\
Mean duration of diabetes mellitus, years & $6.8 \pm 7.9(0.1-40.0)$ \\
Family history of diabetes mellitus & $164(36.5 \%)$ \\
Smoking & $24(5.4 \%)$ \\
Alcohol consumption & $82(18.3 \%)$ \\
Mean BMI & $27.9 \pm 7.8(19-26.5)$ \\
Overweight/obese $(\mathrm{BMI} \geq 25)$ & $332(74.0 \%)$ \\
\hline
\end{tabular}

$\mathrm{BMI}=$ Body mass index

Table 3. Number of antihypertensive medications used per patient

\section{General Findings}

The mean age of the 665 participants was $60.9 \pm 13.1$ years (range 23-93), with slightly more females $(n=380$, $57.1 \%)$ than males ( $\mathrm{n}=285,42.9 \%)$. The general findings concerning cardiovascular risk factors for the total study group are provided in table 1 . One hundred and ninetysix patients were aware that they had been previously diagnosed with hypertension, while 469 (70.5\%) patients were unaware of any previous diagnosis of hypertension.

A known diagnosis of diabetes mellitus was present in 165 patients (24.8\%); of these, $143(86.7 \%)$ had type 2 diabetes and $22(13.3 \%)$ had type 1 diabetes mellitus. The average blood glucose level at clinical examination was $5.5 \pm 3.0 \mathrm{mmol} / \mathrm{l}$ (range 2.2-28.1), and the average duration of diabetes was $1.8 \pm 5.2$ years (range $0.0-$ 48.0).

Of the 464 patients who were classified as either overweight or obese according to their body mass index, 257 (55.4\%) were overweight and 207 (44.6\%) were obese.

\section{Hypertensive Patients}

In this study, 499 patients (75.0\%) had either a known history of hypertension or an elevated blood pressure $(>140 / 90 \mathrm{~mm} \mathrm{Hg}$ ) at the time of the study. The general findings of these patients are provided in table 2 .

Of the 499 hypertensive patients, only 195 (43.4\%) were aware of their hypertensive condition, with the remainder being unaware. Of these 195 patients, blood pressure was adequately controlled $(<140 / 90 \mathrm{~mm} \mathrm{Hg})$ in only $46(23.6 \%)$. Of the total number of hypertensive patients in the study, including those who were unaware of

\begin{tabular}{lc}
\hline Antihypertensive medications & Patients \\
\hline 0 medications & $247(55.0 \%)$ \\
1 medication & $132(29.4 \%)$ \\
2 medications & $51(11.4 \%)$ \\
3 medications & $13(2.9 \%)$ \\
4 medications & $2(0.4 \%)$ \\
5 medications & $1(0.2 \%)$ \\
Unknown number of medications & $3(0.7 \%)$
\end{tabular}

their condition, only 50 (10.0\%) had adequately controlled blood pressure levels.

An overview of the use of antihypertensive medications and the specific number of medications used per patient for all 449 hypertensive patients in this study is provided in table 3.

Of the total number of patients with hypertension, 274 (55.0\%) were not currently taking any antihypertensive medications. The remaining $45.0 \%$ were taking differing numbers of antihypertensive medications each. The majority of these (65.3\%) were receiving only one antihypertensive medication (monotherapy). Three patients reported the use of an unspecified number of antihypertensive medications.

Analysis of the 202 patients on monotherapy showed that the most commonly used antihypertensives were angiotensin-converting enzyme inhibitors and angiotensin II receptor antagonists. The least commonly used were $\beta$-blockers and centrally acting $\alpha 2$ agonists. 


\section{Discussion}

The major findings of this study were a low awareness of hypertension with concomitant low use of antihypertensive medications, resulting in poor control and management of hypertension.

\section{Awareness of Hypertension}

Knowledge of the presence of hypertension is essential before treatment and management is possible. In one study, an enhanced awareness of hypertension in patients showed a significant improvement in patient treatment and outcome [16]. In our study, awareness was very poor; only $43.4 \%$ of patients with hypertension were aware of having had a previous diagnosis. This could reflect poor communication with patients about their medical conditions and/or poor diagnoses by these patients' doctors. However, the contribution of these factors could not be determined within this study design. From patient interviews, it was discovered that most patients do not get their blood pressure checked regularly if they perceive themselves to be healthy.

The level of awareness in this study was similar to that found in a study in Spain, which revealed that only $44.5 \%$ of hypertensive patients were aware of their hypertension [6]. However, in the Spanish study, only $50 \%$ of the patients had hypertension, compared to $75 \%$ of the patients in this study; therefore, the level of hypertension awareness may actually be worse in this Australian study. Another study of a rural Australian population found that $62.1 \%$ of patients were aware of their hypertension [5]. This figure is greater than that found in our study, perhaps due to our incorporation of 3 different rural locations, which may have differing circumstances, and also slightly larger patient numbers. One other large study conducted recently in the USA also reported higher awareness of hypertension (71.8\%) than this study, perhaps indicating that more proficient health care promotion strategies exist in the USA compared to those available in rural Australia [17].

\section{Control and Pharmacotherapy of Hypertension}

We found very poor control of hypertension among our study population. Only $11.1 \%$ of all hypertensive patients had adequately controlled blood pressure based on the 2004 guidelines provided by the National Heart Foundation [11]. This study was the first in Australia to discover such extremely poor levels of hypertension control, and while these levels are comparable to European levels, which range from 5 to $13 \%$, they are much worse than that of many other countries. In Canada, the control of hypertension is estimated to be $21 \%$ and in the USA 36\% [18].

Even in those patients aware of their hypertension, the level of control was still extremely poor, with less than $25 \%$ having a controlled level of blood pressure $<140 / 90$ $\mathrm{mm} \mathrm{Hg}$. In a study by Janus et al. [5], hypertension control was found to be slightly better than in this study, with hypertension controlled in 55\% of women and 35\% of males residing in an area of rural south-eastern Australia. Possible reasons for this difference may be similar to those for awareness, including diverse patient locations and larger patient numbers, but this is not certain.

\section{Usage of Antihypertensive Medications}

Our finding of the use of antihypertensive medications in only $45 \%$ of patients was similar to that of a previous Australian study [5], which documented that only $51.1 \%$ of their hypertensive study participants were receiving antihypertensive treatment.

In our study, monotherapy was the most commonly used antihypertensive treatment option, documented in $29.4 \%$ of patients, a finding that is not consistent with a previous study in which $55 \%$ of patients were on monotherapy [5]. At any rate, there is evidence which supports the view that monotherapy as treatment for hypertension is generally not adequate to control blood pressure at recommended target levels [13]. The findings of the present study support this.

The National Heart Foundation has recommended angiotensin-converting enzyme inhibitors, angiotensin II receptor antagonists, calcium channel blockers and, in patients over 65 years, thiazide diuretics as first-line antihypertensive medication choices [13]. In this study, angiotensin-converting enzyme inhibitors and angiotensin II receptor antagonists were the most commonly prescribed classes overall, followed by calcium channel blockers, $\beta$-blockers and diuretics, findings which appeared to follow the recommendations of the National Heart Foundation. The similarity between our findings and the recommendations of the National Heart Foundation provides an overview of the popularity of the different antihypertensive classes prescribed as monotherapy.

However, the reasons for the low use of antihypertensive medications found in this study were not clear. Possible contributing factors might include a lack of patient follow-up with doctors, cost and accessibility. In rural areas in particular, where some if not all of a patient's income may be derived from the land, the cost of antihypertensive medications may be potentially prohibitive [19], thus possibly reducing the use of these medications. 
Also particular perhaps to rural areas are long distances between patients, healthcare facilities and suppliers. Interruptions and time delays in transport may affect supply of medications, and patients' travelling distances may influence their access to medications and compliance with medication prescriptions [20].

One possible plan of action to improve awareness and management of hypertension in rural areas is to provide free blood pressure checks at local pharmacies and clinics. These places are centrally located in most rural communities, providing easy accessibility, and the promotion of quick, easy, no-cost checks would encourage attendance. Those found to have high blood pressure could then be provided with educational information and advice to visit a doctor for a more thorough health check-up. Any plan that is relatively inexpensive and situated locally would be suitable for most rural Australian areas and people.

A potential limitation of this study is that specific medication dosages were not recorded, which made the analysis of drug dosage and blood pressure control impossible.

\section{Conclusion}

Our data showed that the levels of hypertension awareness and the achievement of optimal blood pressure targets were poor in these patients from a rural Australian community. Also, more than half of the patients with hypertension were not receiving any antihypertensive medications, partially explaining the low levels of hypertension control.

\section{Acknowledgements}

The authors would like to thank Cherryl Kolbe and Beverlie de Jong for technical assistance. The Diabetes Screening Complications Research Initiative received a Charles Sturt University Community of Scholars grant.

\section{References}

1 Australian Bureau of Statistics: 3235.0 - Population by Age and Sex, Regions of Australia, 2007. Canberra, Australian Bureau of Statistics, 2007, Cat. No. 3235.0.

-2 Briganti EM, Shaw JE, Chadban SJ, Zimmet PZ, Welborn TA, McNeil JJ, Atkins RC: Untreated hypertension among Australian adults: the 1999-2000 Australian Diabetes, Obesity and Lifestyle study (AusDiab). Med J Aust 2003;179:135-139.

- 3 Thomas F, Bean K, Pannier B, Oppert J-M, Guize L, Benetos A: Cardiovascular mortality in overweight subjects: the key role of associated risk factors. Hypertension 2005;46: 654-659.

4 Barr E, Magliano D, Zimmet P, Polkinghorne K, Atkins R, Dunstan D, Murray S, Shaw J: AusDiab 2005: The Australian Diabetes, Obesity and Lifestyle Study. Tracking the Accelerating Epidemic: Its Causes and Outcomes. Melbourne, International Diabetes Institute, 2006.

5 Janus ED, Bunker SJ, Kilkkinen A, Namara KM, Philpot B, Tideman P, Tirimacco R, Laatikainen TK, Heistaro S, Dunbar JA: Prevalence, detection and drug treatment of hypertension in a rural Australian population: the Greater Green Triangle Risk Factor Study 2004-2006. Intern Med J 2008;38: 879-886.
-6 Banegas JR, Rodriguez-Artalejo F, de la Cruz Troca JJ, Guallar-Castillon P, del Rey Calero $\mathrm{J}$ : Blood pressure in Spain: distribution, awareness, control, and benefits of a reduction in average pressure. Hypertension 1998; 32:998-1002.

7 Sunderland B, Burrows S, Joyce A, McManus A, Maycock B: Rural pharmacy not delivering on its health promotion potential. Aust J Rural Health 2006;14:116-119.

8 Ala L, Gill G, Gurgel R, Cuevas L: Evidence for affluence-related hypertension in urban Brazil. J Hum Hypertens 2004;18:775-779.

$\checkmark 9$ Wang L, Wei T: Blood pressure control in patients with hypertension: a communitybased study. Clin Exp Hypertens 2006;28: 41-46.

10 Kolbe C, Jelinek HF: Prevalence and management of hypertension in a rural community. The Australian Health and Medical Research Congress, Sydney, 2004, p 292.

11 Heart Foundation: Hypertension Management Guide for Doctors 2004. National Heart Foundation of Australia, 2003.

12 Wang L: Physician-related barriers to hypertension management. Med Princ Pract 2004; 13:282-285.

13 Heart Foundation: Guide to Management of Hypertension 2008: Assessing and Managing Raised Blood Pressure in Adults. National Heart Foundation of Australia, 2008.
14 Jelinek H, Kolbe C, Wang L, Oxbrow D: Identification of hypertension and efficacy of treatment in a rural Australian population. Clin Exp Hypertens 2008;30:359-366.

15 Jelinek HF, Wilding C, Tinley P: An innovative multi-disciplinary diabetes complications screening program in a rural community: a description and preliminary results of the screening. Aust J Prim Health 2006;12: 14-20.

16 Wang L, Li J: Role of educational intervention in the management of comorbid depression and hypertension. Blood Press 2003;12: 198-202.

17 Cutler JA, Sorlie PD, Wolz M, Thom T, Fields LE, Roccella EJ: Trends in hypertension prevalence, awareness, treatment, and control rates in United States adults between 1988-1994 and 1999-2004. Hypertension 2008;52:818-827.

18 Wolf-Maier K, Cooper RS, Kramer H, Banegas JR, Giampaoli S, Joffres MR, Poulter N, Primatesta P, Stegmayr B, Thamm M: Hypertension treatment and control in five European countries, Canada, and the United States. Hypertension 2004;43:10-17.

19 Adams AS, Soumerai SB, Ross-Degnan D: Use of antihypertensive drugs by Medicare enrollees: does type of drug coverage matter? Health Aff 2001;20:276-286.

20 Nemet GF, Bailey AJ: Distance and health care utilization among the rural elderly. Soc Sci Med 2000;50:1197-1208. 